\title{
Editorial
}

\section{Una articulación necesaria para el buen desempeño de los programas en salud pública}

La pasada ola invernal que azotó al país durante el primer semestre de este año, dejó más de cuatro millones de damnificados. El análisis de las imágenes geoespaciales pronostican una segunda ola invernal antes de que termine el presente año y, probablemente, el número de damnificados aumentará trayendo consigo mayor desolación e impactos negativos en la economía y en la salud teniendo en cuenta que menos del $2 \%$ de las obras priorizadas por el gobierno para mitigar los efectos del invierno se han cumplido. El análisis de las causas y de las consecuencias arroja muchas variables y una de las principales razones es que el país no está preparado, a pesar de las claras advertencias de lo que se avecinaba por parte de los expertos, en el manejo del clima y de las imágenes satelitales.

En lo que refiere a salud pública, se presenta una situación similar: el país tampoco está preparado para prevenir y controlar la transmisión de las enfermedades tropicales. Las cifras, a pesar del subregistro, muestran una tendencia al aumento y no a la reducción de los casos de leishmaniasis, dengue, enfermedad de Chagas, helmintiasis, enfermedades diarreicas y malaria, para mencionar algunas.

Latinoamérica es un continente megadiverso y muchas de sus regiones presentan una privilegiada ubicación geográfica en los Andes ecuatoriales húmedos y vastas regiones tropicales que presentan las condiciones de temperatura y humedad propicias para el desarrollo de una inmensa variedad de parásitos y otros agentes infecciosos que afectan a la población humana y animal.

Muchos de estos agentes patógenos se establecieron en el continente americano hace millones de años y desarrollaron mecanismos de transmisión que utilizaron a los animales silvestres como reservorios y fuente de alimento, y, más tarde, se incorporaron a los ciclos de transmisión los primeros pobladores humanos. Se establecieron así las zoonosis que aún hoy en día persisten y ocupan extensas áreas geográficas de todo el continente.

Debido a estas y a otras características propias, las zoonosis no se pueden erradicar fácilmente y, por lo tanto, requieren de estrategias particulares para evitar la transmisión de las infecciones a los humanos y a sus animales domésticos.

Pareciera, entonces, que con las consideraciones expuestas, el panorama de la reducción de la carga de las enfermedades desatendidas fuera bastante desalentador. Quizá lo es, pero no debido a la ausencia de herramientas y de estrategias sino por un divorcio entre la academia, los administradores de la salud y la industria farmacéutica.

El generador de las políticas de salud podría analizar el valor de las investigaciones desde su perspectiva y argumentar que el dinero empleado en investigación debería usarse para salvar vidas ahora y que el tratamiento es más importante que la prevención, y que ambos son más importantes que la investigación. También podría argumentar que la investigación toma demasiado tiempo y no genera resultados inmediatos y aplicables, sino que, por el contrario, crea herramientas más costosas y sofisticadas, que no se pueden aplicar en los países endémicos y que sólo la investigación aplicada y operativa es relevante, para finalizar argumentando que una buena administración es lo único que se necesita.

Por su parte, los investigadores podrían argumentar que su responsabilidad es investigar y que los hallazgos obtenidos para prevenir y controlar las enfermedades no son de su incumbencia.

Por otro lado, la industria farmacéutica podría argumentar que invertir en el desarrollo de nuevos medicamentos o moléculas para producir nuevos fármacos para el tratamiento de las enfermedades de los países en desarrollo no es rentable y que, por lo tanto, no se debe invertir en el desarrollo de nuevos productos sino solamente en aquellos que dejen suficientes ganancias.

Recordemos la historia de la gran epidemia de poliomielitis. A comienzos de la década de los años cincuenta del siglo XX, el gobierno de los Estados Unidos de América se vio enfrentado a tomar una seria decisión para combatir los miles de casos de poliomielitis que afectaban a la población. Una posibilidad era seguir invirtiendo en costosos pulmones de acero, que eran una herramienta crucial para el tratamiento de las personas paralizadas por la enfermedad. Para los pacientes con parálisis temporal, el respirador de 
presión negativa les ayudaba a respirar mientras se recuperaban, y los pacientes con parálisis permanente debían limitarse al uso permanente de los pulmones de acero para el resto de sus vidas.

Las salas de los hospitales se llenaron de pulmones de acero durante el brote de poliomelitis de los años de 1940 y 1950, y los costos eran insostenibles. Entonces, surgió el dilema: invertir en más y mejores pulmones de hierro, o invertir en un sueño: la vacuna contra la infección viral. Cinco años más tarde, el sueño se hizo realidad: Jonas Salk desarrolló la primera vacuna contra la poliomielitis.

Esta historia es un ejemplo de cómo las autoridades de salud tomaron una decisión acertada y concertada con la academia y la industria, que trajo un enorme beneficio no solamente al sistema de salud de los Estados Unidos sino a toda la humanidad.

Como éste hay innumerables ejemplos en la historia de la biomedicina, que demuestran la necesidad de que los tres actores actúen de manera concertada, respetando las características propias de cada disciplina.

Por el contrario, si las políticas de Estado dirigen los fondos del apoyo a la investigación en ciencia y tecnología hacia las acciones que los responsables de la administración de los programas de salud deberían haber adelantado -y no lo han hecho-, se limita el desarrollo de la investigación libre impidiendo la generación de nuevos conocimientos que pudieren beneficiar a los programas de salud.

La academia constituye un pilar fundamental para la generación de nuevos conocimientos y una de sus misiones es adelantar investigación libre para que los resultados obtenidos sean dados a conocer para su adecuada implementación y utilización en los diferentes sectores de la sociedad.

La otra misión de la academia es la formación de profesionales que, en el caso de la salud, hay que mirar con detenimiento y analizar si se está cumpliendo cabalmente con la formación integral de los profesionales. Después de muchos años de incursionar en el campo de la salud pública, da la impresión que los profesionales de la salud no reciben la formación necesaria para atender a los pobladores más necesitados de las regiones más apartadas que son aquellas personas que viven en extrema pobreza en donde las enfermedades tropicales se manifiestan con mayor gravedad. Es responsabilidad de la academia formar profesionales íntegros en todos los campos de la salud y, por lo tanto, revisar periódicamente los contenidos de las diferentes asignaturas y prácticas de laboratorio.

EI XX Congreso de la Federación Latinoamericana de Parasitología (FLAP) se celebra en la Universidad de los Andes conjuntamente con el XV Congreso de la Asociación Colombiana de Parasitología y Medicina tropical (ACPMT). La larga trayectoria de las dos corporaciones refleja una actividad sostenida a lo largo de sus 40 y 46 años de vida, respectivamente. Ambas son entidades que promueven el desarrollo científico y tecnológico en el área de la medicina tropical y la parasitología y, además de servir de foro para el diseño de políticas y estrategias para mitigar los problemas de la salud pública y reducir la carga de las enfermedades tropicales, convocan a todos los actores que deben estar presentes para que de manera conjunta se tomen las decisiones más acertadas para cumplir con el propósito de prevenir y mejorar los problemas de salud que aquejan a las comunidades más afectadas.

Se discuten temas novedosos que deben ser incorporados en las agendas de los administradores de la salud, tales como la salud geoespacial, la aplicación de modelos matemáticos de las diferentes enfermedades bajo diversos situaciones, la epidemiología molecular, la ecología sensorial en insectos vectores, la proteómica y la genómica aplicadas a los diferentes agentes patógenos al igual que la bioinformática, el desarrollo de nuevas vacunas y el desciframiento de los genomas de los agentes infecciosos.

Es preciso enfrentar con mente abierta los nuevos retos que ofrece la ciencia y salir de los esquemas clásicos, muchas veces obsoletos e inoperantes, y aceptar los cambios que vienen de la mano con el desarrollo tecnológico y científico; son las nuevas tendencias de la ciencia que ofrecen modernos y acertados campos de acción y que pueden convertirse en herramientas poderosas para ser aplicados en las diferentes situaciones en las que debe actuar la salud pública.

Los temas que se publican en el presente suplemento constituyen un valioso aporte de investigadores nacionales e internacionales interesados en ofrecer los resultados de sus investigaciones para un mejor vivir de la poblaciones afectadas por las enfermedades asociadas a la pobreza y a la mala calidad de vivienda.

Ojalá, el esfuerzo de congregar a todos los actores responsables sirva para integrar acciones que permitan tomar las decisiones más adecuadas en beneficio de las poblaciones afectadas.

Felipe Guhl Nannetti

Presidente, Federación Latinoamericana de Parasitología 